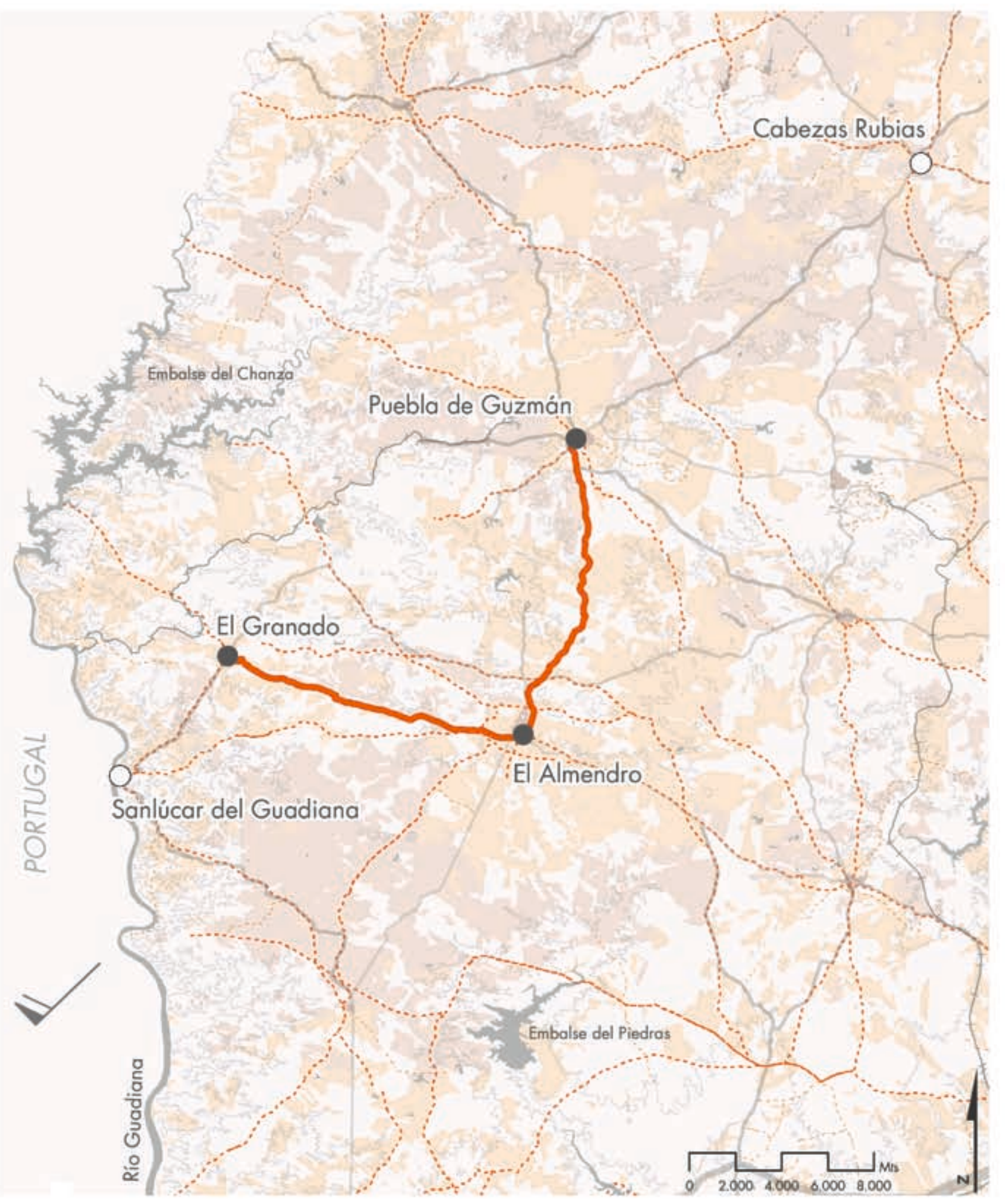

Hitos de la ruta

Hitos asociados

Caracterización paisajistica

Carretera nacional

Dehesa

Carretera secundaria

Tierra calma

Vias pecuarias

Otros

Red de caminos

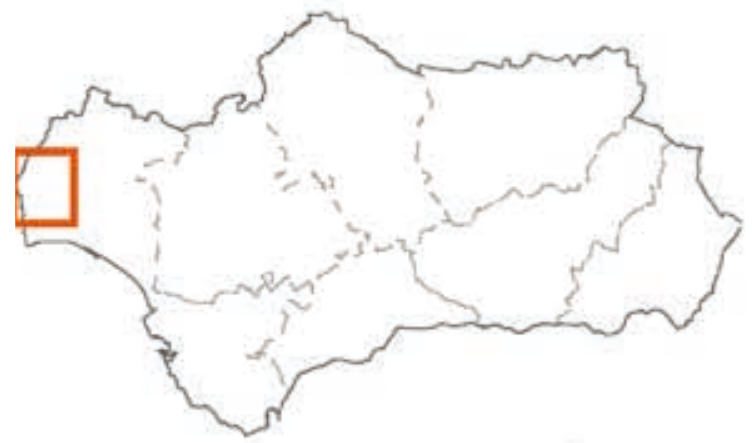

Localización de la ruta. Mapa: Pilar

Zafra y David Villalón, IAPH 


\section{Ingenios de aire. Molinos de viento en la comarca del Andévalo}

Pilar Zafra Costán, Centro de Documentación del IAPH
- La aventura va guiando nuestros pasos mejor de lo que acertáramos a desear; porque ves alli, amigo Sancho Panza, donde se descubren treinta o pocos más, desaforados gigantes, con quien pienso hacer batalla...

- ¿Qué gigantes? -dijo Sancho Panza.

- Aquellos que alli ves -respondió su amo-, de los brazos largos, que los suelen tener algunos de casi dos leguas.

- Mire vuestra merced -respondió Sancho- que aquellos que alli se parecen no son gigantes, sino molinos de viento, y lo que en ellos parecen brazos son las aspas, que, volteadas del viento, hacen andar la piedra del molino...

Don Quijote de la Mancha; capítulo VIII

Miguel de Cervantes y Saavedra

Susurra el viento historias de antaño, modos de vida y culturas del trabajo que aún perduran en el imaginario colectivo; que aún se tornan presentes en aquellos gigantes que tan de cabeza trajeran al valeroso hidalgo don Quijote; que aún se erigen orgullosos, arriba en colinas, lomas y cerros, modulando la visual del paisaje en el que se asientan.

Eolo en su eterno discurrir no cesa en su empeño: henchir las velas abiertas de aquellas naves que en su quehacer diario, en su girar, convertían el esfuerzo y el ingenio en el pan nuestro de cada día.

Los molinos de viento representan una constante a lo largo de la historia. La fascinación que ha suscitado este tipo de construcciones se debe, en gran medida, a que constituyen uno de los primeros artilugios con que el hombre supo aprovechar la fuerza inagotable que proporcionaba el viento. Un avance para la civilización que lo acompañó desde que éste abandonara el nomadismo e iniciara la domesticación de plantas, descubriendo el valor nutritivo de sus frutos -trigo, mijo, cebada,...- como base para su sustento vital. La invención y posterior evolución tecnológica de mecanismos que permitiesen molturar el grano con el fin de obtener harina para la elaboración de pan... no se hizo esperar.

Desde su forma más rudimentaria, utilizándose para el triturado del grano dos piedras pulidas, hasta la introducción de nuevas soluciones, como la incorporación del movimiento giratorio en la molienda (molineta) o el empleo de la fuerza humana o animal (molinos de sangre), el aprovechamiento de la energía eólica para multiplicar la producción, por medio de maquinarias complejas, supuso el avance más importante en la evolución y perdurabilidad de esta actividad productiva.

Tras la introducción de este ingenio, por parte de los últimos cruzados que regresaron de Tierra Santa y por los árabes asentados en la zona del Mediterráneo, según la hipótesis más admitida, la singular silueta de estos molinos de viento llegó a constituirse en un elemento familiar en los campos de toda Europa, fundamentalmente a partir de los siglos XIV, XV y XVI.

A nivel nacional, según Julio Caro Baroja, la presencia de estas construcciones, que empleaban la corriente del aire para generar una fuerza motriz con fines utilitarios, se concentró principalmente en La Mancha y El Andévalo onubense.

La comarca andevaleña se ubica en el centro geográfico de la provincia de Huelva a caballo entre la serranía y la llanura sedimentaria onubense. Emplazada al sur de la sierra de Aracena y Picos de Aroche, extendiéndose por el oeste desde la raya de Portugal hasta la Cuenca Minera de Río Tinto en el este, y limitando en su parte baja con el Condado, el Litoral y la zona periurbana Campiña, esta comarca se caracteriza fundamentalmente por su topografía suavemente acolinada, con relieves de poca envergadura (cabezos, altos y cumbres). Abierto a los vientos atlánticos, en El Andévalo, arquitectura y tecnología popular se han adaptado y desarrollado tradicionalmente en función de los elementos que ofrece el medio y las necesidades de sus moradores.

La generalizada presencia de molinos de viento en muchos de los municipios de la comarca subraya su histórica eficiencia en la transformación de uno de los productos básicos de la tríada mediterránea: el trigo para la producción de harina. No en balde, la molienda se perfila como una etapa decisiva en el ciclo del cereal para la supervivencia de las comunidades campesinas, cuya dieta era poco variada y basada en el consumo de pan y sus derivados. 


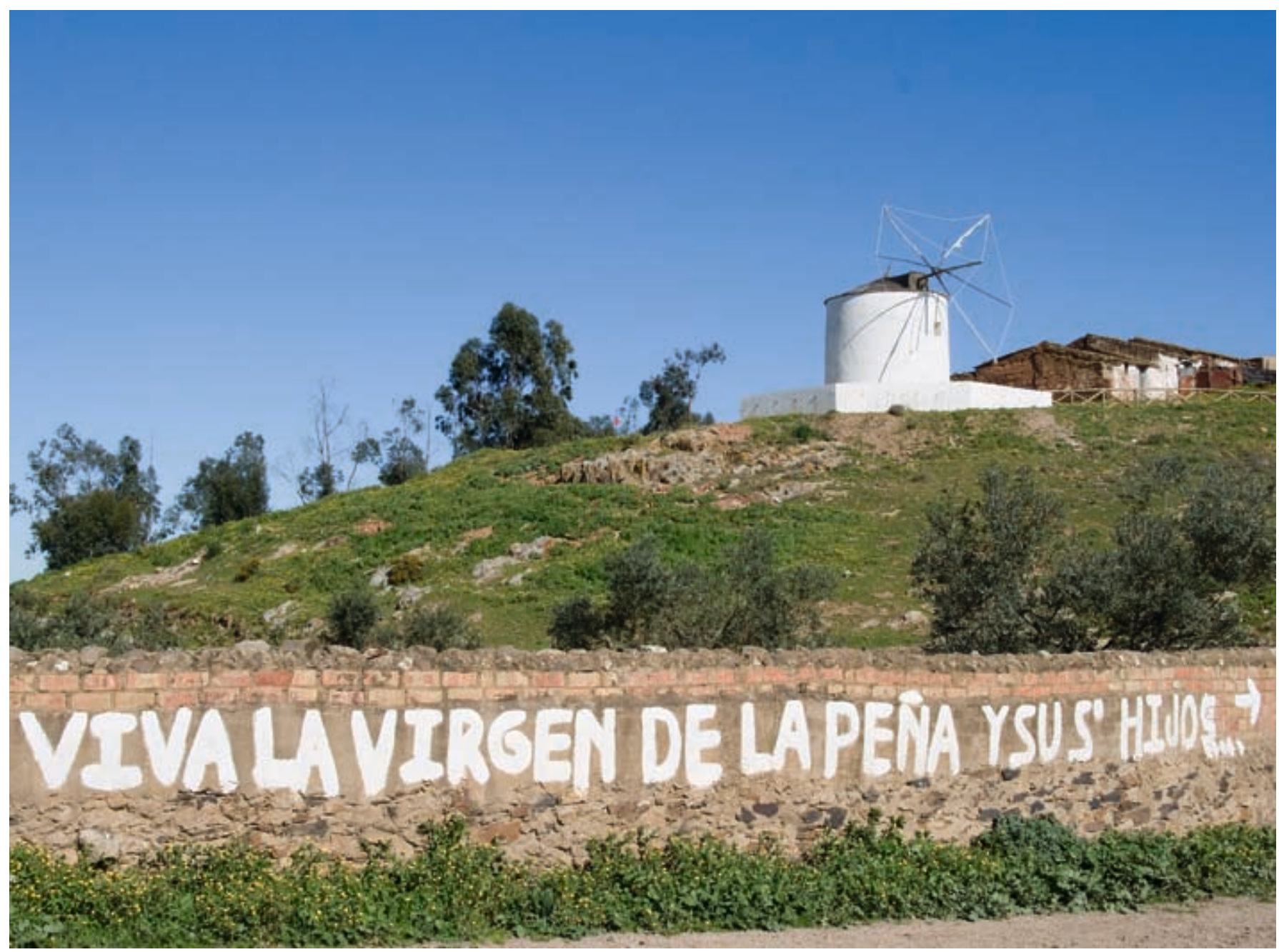

Molino del Pozo de Bebé (La Puebla de Guzmán), ubicado en la salida del camino hacia la ermita de la Virgen de la Peña. En días de romería es aquí donde hombres y mujeres se concentran antes de iniciar el recorrido hacia la ermita, cantando sus coplas de monta. Foto: Aniceto Delgado Méndez, IAPH

Este proceso de adaptación natural, ocurrido en un entorno tan singular, confiere a esta zona un especial valor antropológico y arquitectónico. Entre otras ventajas, su presencia, por lo general, en las cercanias de las poblaciones y de las tierras de cultivo, al no precisar más elemento que un promontorio despejado para su instalación, favoreció su acceso y elección por parte de la población, en detrimento de los molinos de agua, muy extendidos pero ubicados en lugares apartados y de difícil comunicación. Los molinos de viento, en este sentido, constituyen un testimonio excepcional que ha de ser analizado en base a los aspectos ecológicos, geográficos, territoriales, económicos, sociales y culturales que determinaron su aparición, evolución y permanencia.

El Granado se erige orgulloso en el límite más occidental de la provincia de Huelva. La antigua Praesidio romana se emplaza en un terreno accidentado surcado por los ríos Guadiana y la ribera del Chanza, limites naturales que hacen las veces de frontera con Portugal. La vinculación con aquel país ha marcado el devenir histórico de este municipio, tal y como lo revelan aquellos "gigantes imaginarios" que un día desafiaron al viento: sus molinos, similares en forma y factura a aquellos que aún se divisan en las estribaciones del Algarve y el Alentejo lusitano.
Estas construcciones, de un marcado carácter industrial, permanecieron en activo hasta bien entrado el siglo XX, viviendo incluso un periodo de reactivación muy significativo durante la Guerra Civil y los primeros años de la posguerra. No obstante, el inicio del consumo de harina industrial, procedente en su mayoría de grandes fábricas dotadas de una mayor capacidad de producción, provocó el progresivo cierre de estos molinos.

Su tipología responde a la conocida como de torre. Como su propio nombre indica es de planta circular y forma troncocónica, de unos siete metros y medio de altura, un diámetro exterior en la base de unos ocho metros y una anchura de muro de metro y medio. Realizado en piedra y arcilla, posteriormente enfoscado y encalado, consta de dos pisos: uno inferior, que hacia las veces de vivienda del molinero; y uno superior, comunicado por medio de una escalera adosada al muro, donde se situaba todo el engranaje para el funcionamiento del molino. La movilidad de la techumbre de madera, suspendida sobre rodetes y recubierta por una capa de brezo al exterior, permitía que las aspas del molino se orientaran según la dirección del viento, lo cual garantizaria el movimiento de las piezas para posteriormente proceder a la molienda del grano.

Entre los ejemplos que aún perduran en esta localidad onubense destaca un ingenio datado en el siglo XVIII. Emplazado en un 

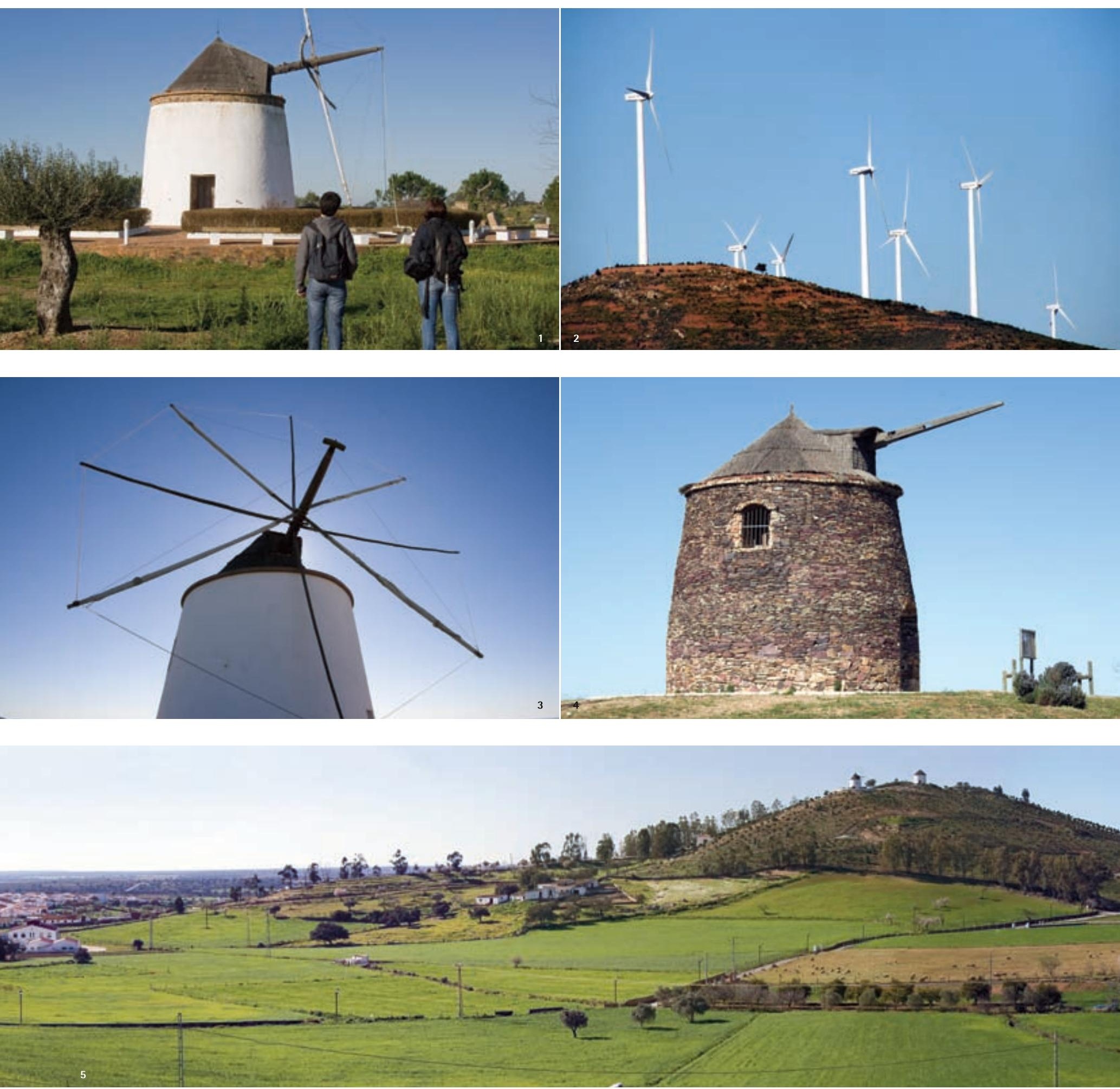

1. Vista del molino popular industrial del siglo XVIII, ubicado en las inmediaciones de la localidad de El Granado. Foto: Aniceto Delgado Méndez, IAPH

3. Molino Pie del Castillo en El Almendro. Foto: Aniceto Delgado Méndez, IAPH

5. Panorámica del municipio de El Almendro, al fondo presidiendo la cumbre de

2. Parque eólico de El Granado. Foto: Aniceto Delgado Méndez, IAPH

4. Vista general del Molino de la Horca. La Puebla de Guzmán.

cerro donde se emplazan sus molinos de viento. Foło: Aniceto Delgado Méndez, IAPH

Foto: Aniceto Delgado Méndez, IAPH

El inicio del consumo de harina industrial, procedente en su mayoría de grandes fábricas dotadas de una mayor capacidad de producción, provocó el progresivo cierre de estos molinos 


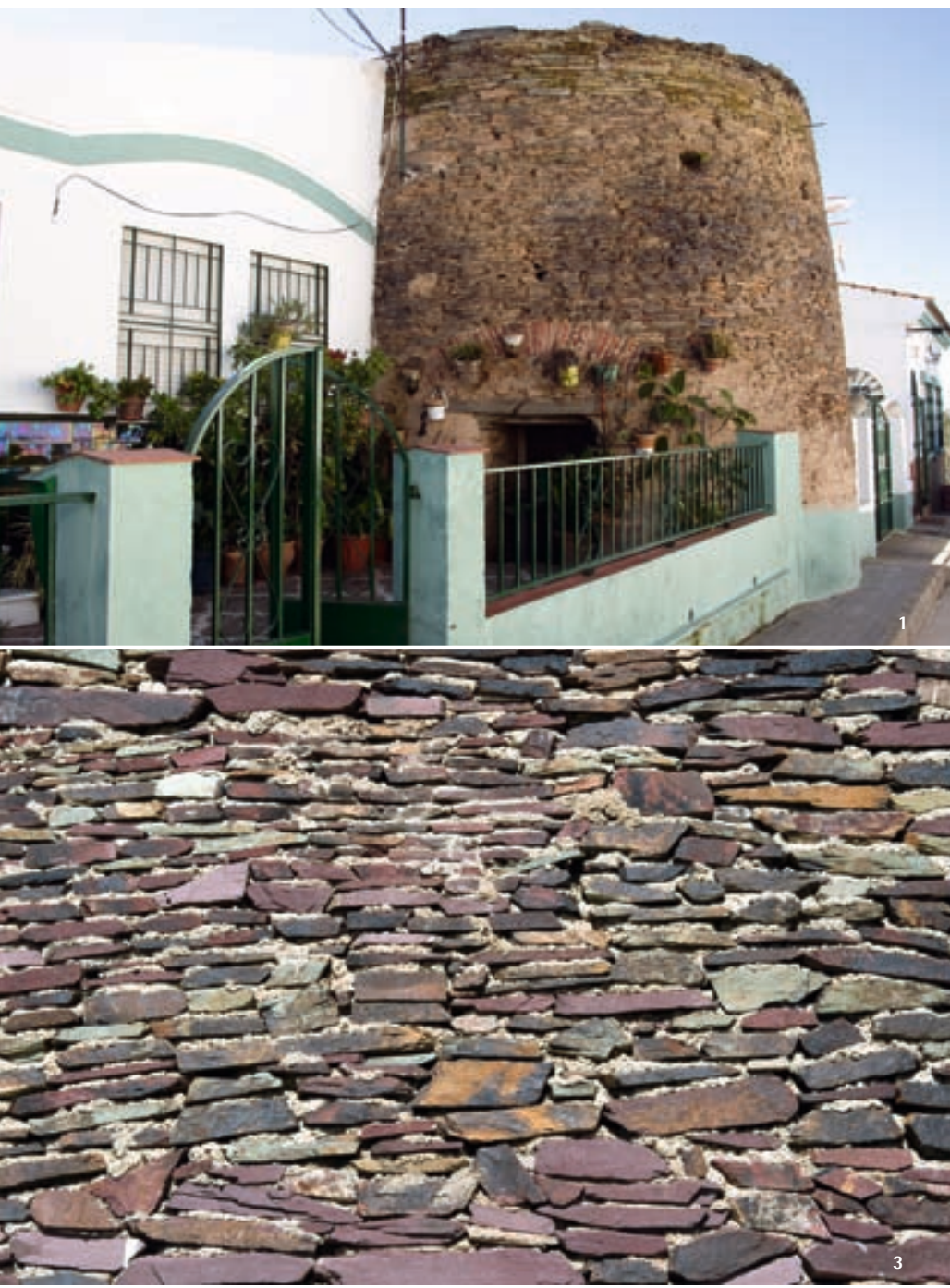

1. Restos de un molino, que ha pasado a formar parte de una vivienda particular (La Puebla de Guzmán). Foto: Aniceto Delgado Méndez, IAPH

3. Detalle de mampuesto de piedra (Molino de la Horca, La Puebla de Guzmán). Foto: Aniceto Delgado Méndez, IAPH

altozano, desde el que se divisa toda la extensión del municipio, hace un guiño histórico a la cada vez más frecuente proliferación de parques eólicos en sus inmediaciones. Su reciente rehabilitación, que ha empleado piezas traídas expresamente de Portugal, por la similitud tipológica que guardan, ha permitido la recuperación de su funcionamiento original.

El territorio donde El Almendro se asienta ocupa una estrecha franja de terreno que toca en su extremo oeste con la frontera de Portugal, limitando al norte con el término municipal de La Puebla de Guzmán y al suroeste con El Granado.

Actualmente restaurado para su nueva puesta en marcha, reproduciendo la maquinaria originaria, el molino Pie de Castillo preside la cumbre del cerro donde se sitúa, ante el cual se asienta el actual caserío de El Almendro. Se trata de uno de los pocos molinos de trigo que perduran de los construidos en el siglo XVIII, época en la que éstos proliferaron en la localidad.

La maquinaria de estos ingenios se dividia en dos partes fundamentales: los elementos del eje horizontal y los relativos al eje

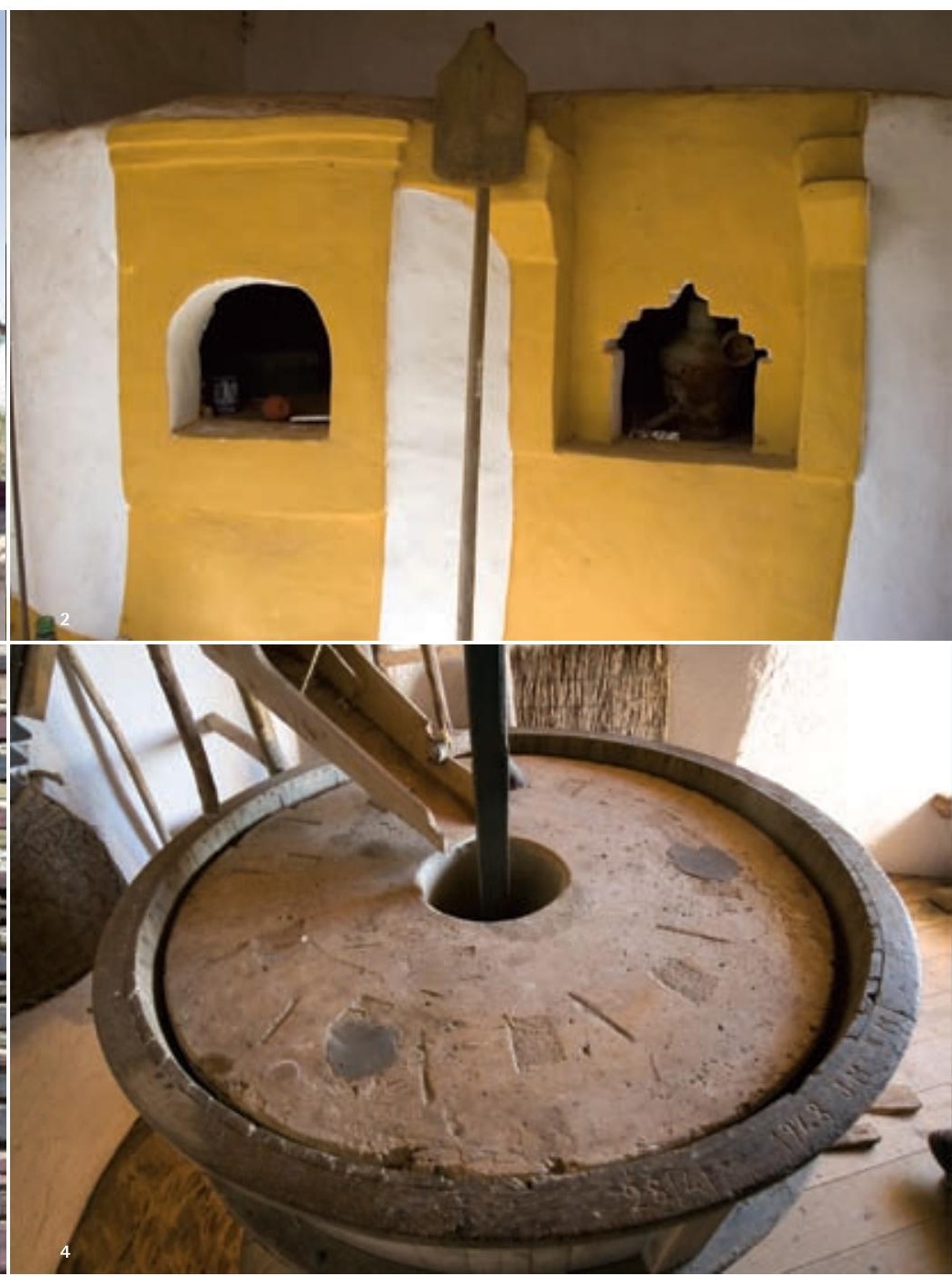

2. Horno de pan tradicional ubicado en vivienda de grandes propietarios (La Puebla de Guzmán). Foto: Aniceto Delgado Méndez, IAPH

3. Piedras de moler, compuestas por la solera (fija) y la volandera (móvil) (EI Granado). Foto: Aniceto Delgado Méndez, IAPH

vertical. Entre los primeros, y al exterior, destacaban las berlingas. Ocho aspas en total, cuatro de vela y cuatro de puño, llamadas asi porque en ellas se amarraba el velamen cuando se desplegaba para aprovechar las corrientes de aire. El movimiento circular de las aspas era transmitido al injerto, el eje horizontal del molino, que ya en su interior perforaba la rueda de engrane, cuya finalidad era multiplicar las revoluciones de una a cinco, transfiriéndolas por medio de la linterna al eje vertical. Dicho eje, conocido como tenazón, atravesaba las dos piedras de moler, la solera, fija, y la volandera, móvil, que giraba sobre aquélla molturando el grano. Todo el peso del sistema apoyaba en el suelo, donde una palanca, el alivio, regulaba la presión de las muelas, factor que determinaba la calidad de la harina resultante. Para suministrar el grano a la piedra se empleaba la tolva, depósito de madera con forma de pirámide invertida, cuyo vértice estaba conectado con la panereta, elemento que regulaba la entrada de grano por el ojo de la piedra volandera, garantizando su flujo constante.

Desde los paisajes ondulados, cubiertos de dehesas, a las profundidades abiertas por los mineros, desde las grandes extensiones sembradas de olivos hasta el promontorio que alberga la ermita 

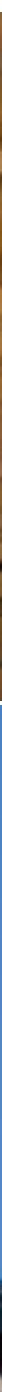

1. Unión del injerto, eje horizontal, y las berlingas, nombre con el que se denominaba a sus ocho aspas (El Granado). Foto: Aniceto Delgado Méndez, IAPH 3. El molino Pie del Castillo preside la cumbre del cerro ante el que se asienta el actual caserío de El Almendro. Foto: Aniceto Delgado Méndez, IAPH

de La Peña, el territorio que ocupa La Puebla de Guzmán aún conserva, salpicados en los bordes de su perimetro, un importante conjunto de molinos de viento que, antaño, iniciaron la mecanización de las tareas agrícolas.

Testigos de la gran importancia que tuvo el cultivo de cereales en el municipio para la economía local, en la Puebla de Guzmán se contabilizaron hasta dieciocho molinos de viento en hacia el año 1880, llegando incluso a mantenerse en activo hasta el año 1924. Se calcula que, durante un buen día ventoso, los molinos puebleños llegaban a moler hasta una tonelada de trigo, unas 24 fanegas de entonces. En la actualidad, tan sólo se han mantenido en pie algunos de ellos, de entre los cuales han sido restaurados y, por ende, devueltos a sus habitantes dos de ellos: el de La Horca y el del Pozo de Bebé. Este último se localiza junto a un grupo de otros dos no rehabilitados en la salida del camino hacia la ermita de la Peña, por encima del mítico pozo que le da nombre. Es aqui donde, en los dias de la famosa Romería de La Peña, se concentra la caballería después de recorrer las calles del pueblo, donde hombres y mujeres se preparan para recorrer el polvoriento camino cantando sus coplas de monta.

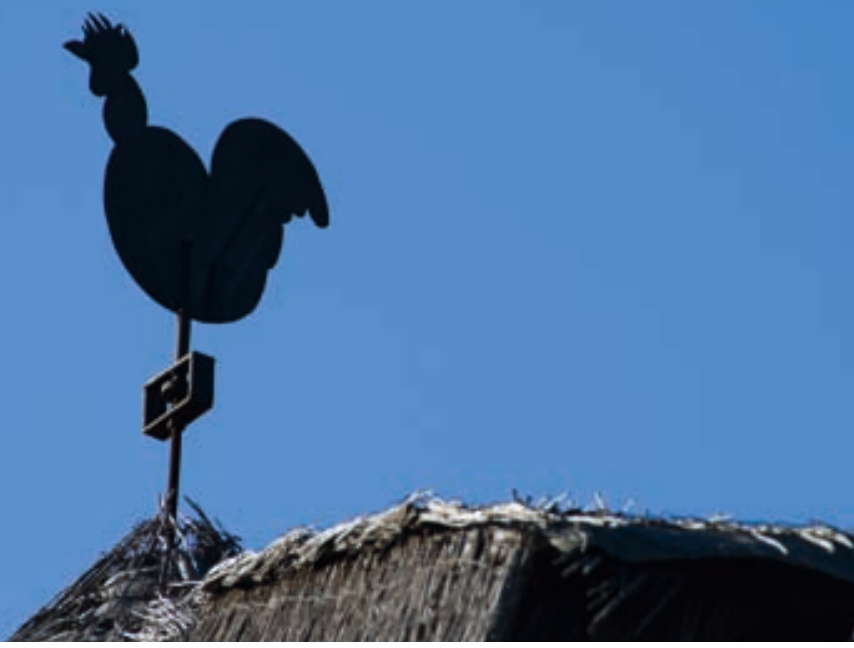

2. Detalle de la rueda de engrane (El Granado).

Foto: Aniceto Delgado Méndez, IAPH

4. Veleta que corona la techumbre de madera del molino, recubierta por una capa de brezo en el exterior (El Granado). Foto: Aniceto Delgado Méndez, IAPH
El funcionamiento de molinos como el de La Horca, situado la salida de la carretera hacia Cabezas Rubias, requería de una destreza que el oficio, transmitido de generación en generación, proporcionaba. Conocimientos, saberes y procedimientos personificados en la figura del molinero. Esta era una profesión dura y compleja. Dura por el constante acarreo de sacas. Cargar y descargar las bestias, subir la molienda al piso de arriba, quitar y poner velas, desmontar y picar las piedras, llevar el control de todo... y sin horario, hasta que el viento durara o quedara grano por moler. Y compleja por la variedad y cantidad de conocimientos necesarios. De su destreza en el cálculo de la entrada de grano, en el control fuerza del viento y el estado de la piedra, dependería la calidad de la harina y, por ende, la fama del molinero.

Molinos y molineros son ya historia. Vestigios de un pasado cercano y olvidado que han de ser preservados por constituir un fiel reflejo de las transformaciones acaecidas en la articulación socieconómica de nuestra historia. Pues estos orgullosos cíclopes, que aún siguen animando con su impronta la quietud del paisaje andevaleño, resumen una de las más eficaces respuestas de adaptación al medio para satisfacer nuestras necesidades más primarias. 


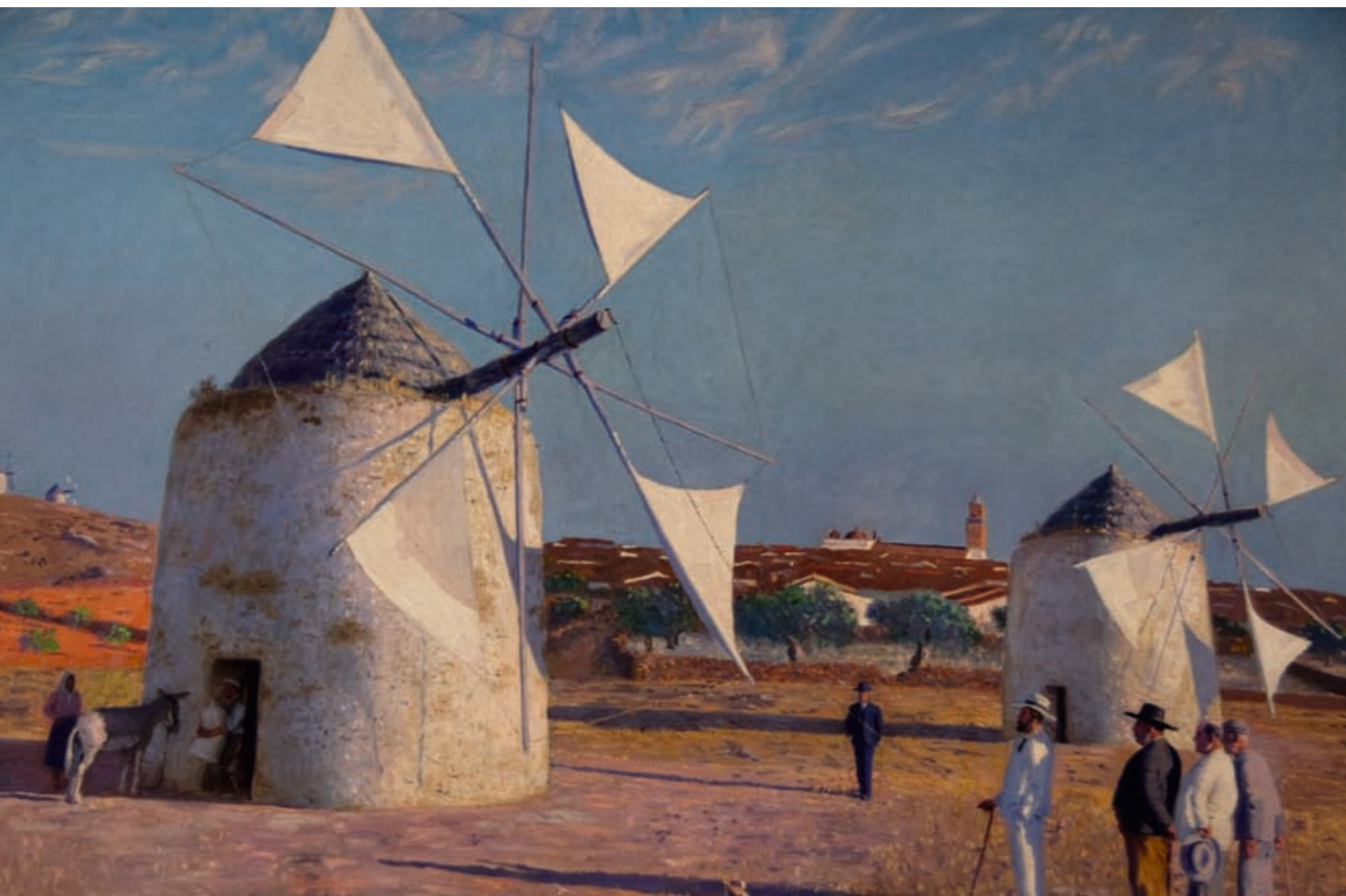

"Molinos que trabajaban en La Puebla de Guzmán hasta aproximadamente el año 1920. Fue pintado en 1950 ya no quedan sino restos." Manuscrito del autor al dorso del lienzo. Sebastián García, 1950. Foto: Aniceto Delgado Méndez, IAPH

\section{Imagen contemporánea, reelaboraciones del paisaje}

El territorio geográfico se reivindicará en cada momento para ser un producto distinto. En la línea de los discursos actuales, el espacio no es sino la traslación de un producto social (maneja identidades, transforma usos, genera ansiedades de nueva utilización y pone en valor aquello que parece que está de acuerdo con tendencias, relaciones de género...).

Quizás en la identidad como elemento primordial de la cultura es donde las imágenes que queramos proyectar y fabricar sean el motor más importante. Espacios candidatos a continuos cambios que tratan de hacer visible lo invisible además de atractivo o rentable aquello que va cayendo en desuso.

El arte es, sin duda, un elemento de reelaboración del hecho diferencial y en su caso una especificidad que busca reconocimiento, distinguible de otros, diferente, atractivo, "único". El paisaje ha servido de ventana para expresiones plásticas diversas y creación de ideas. El arte contemporáneo se ha abonado en su plástica de la misma manera que el refuerzo de la identidad en la mirada, sobre todo en la fotografía. Asistimos en estos 15 últimos años a la frecuente in- cursión en temas urbanos, en la (nueva) desintegración de las clases, diversidades en un mismo espacio o rescate de la arqueología industrial.

En la comarca del Andévalo hay una relación de límites con la vecina Portugal (Algarve y Alentejo) y la marca de la minería introduce otras culturas externas y posibilita una burguesía escogida. Paradójico es encontrar en Nerva un Museo de arte contemporáneo (1999) con amplia colección (nueva pintura contemporánea española) que agrupa a un gran número de críticos (Juan $\mathrm{M}$. Bonet), galeristas (Juana de Aizpuru) o artistas (Quico Rivas), que elaboran relaciones con el paisaje en esta y otras comarcas limitrofes, aunque para la identificación señalética y como entrada del pueblo es la torre erguida, el malacate minero quien nos recibe.

Pero también existe un riesgo hacia la tematización y homogenización al clonar imágenes reconocibles y que contradice su pretendida unicidad creando aterritorialidad. Un buen ejemplo es la incorporación de nuevos elementos escultóricos (escultura para el lugar), además de los monumentales, para definir nuevas exigencias en la distribución espacial.
Objetos decorando rotondas o hitos arquitectónicos casi escultóricos (nuevo puente sobre el Guadiana). Referentes escultóricos identitarios realizados en los últimos años (las danzas en San Bartolomé de la Torre o el cante flamenco en Alosno, busto a Paco Toronjo) al igual que en otras zonas y poblaciones.

Prácticas artísticas reveladoras y sorprendentes inciden en este espacio por su importancia como el Museo de Aracena, con más de cuarenta y tres esculturas de autores contemporáneos bajo el proyecto del escultor Pepe Noja en 1972, pionero en España junto con el de la Castellana en Madrid.

Además se está releyendo las vivencias de espacios de sociabilidad con nuevas apropiaciones. El arte, además de documentar estos elementos como sucesión de hechos, propone la diferencia en la mirada; sin duda es ésta la que reelabora el paisaje.

José Carlos Roldán Saborido

Conservador del Centro Andaluz de Arte Contemporáneo 
AGUDO TORRICO, J. Danzas Rituales. En: Enciclopedia General de Andalucía. [Málaga] : C\&tT Editores, 2004, vol. 7, p. 2772-2775*

CANTERO, Pedro A. Licores, aguardientes y vinagres. En: Rodríguez Iglesias, Francisco (dir.). Proyecto Andalucía, Antropología. [Sevilla], 20012005, vol.1: Economía y tecnología. p. 216-226 *

CARO BAROJA, Julio. Fiestas populares de Huelva : Romería de la Virgen de la Peña-Puebla de Guzmán. Separata de : Estudios sobre la vida tradicional española. [Barcelona : Península, 1968], p. 17-54

CARO BAROJA, Julio. Tecnología popular española. Barcelona: Galaxia Gutemberg : Círculo de Lectores, 1996 *

CARRERO CARRERO, Antonio José. Los molinos de viento. La molienda en Cabezas Rubias. En : Márquez Domínguez, J. Antonio. Artes, costumbres y riquezas de la provincia de Huelva. Huelva : Huelva Información, D.L., 1997

La CONSTRUCCIÓN del paisaje contemporáneo [catálogo de exposición organizada por CDAN, Fundación Beulas, 23 mayo al 28 septiembre 2008]. Huesca : Centro de Arte y Naturaleza (CDAN), Fundación Beulas, 2008 *

CRUZ INFANTE ESCUDERO, Manuel de la; ENCINAS RODRÍGUEZ, Juan Jesús. Anises y licores. El aguardiente de Zalamea la Real. En : Artes, costumbres y riquezas de la provincia de Huelva. Huelva : Huelva Información, 1997. p. 1261-1276

DOMÍNGUEZ CORNEJO, M. Zalamea la Real. Aproximación histórica. Sevilla : Ayuntamiento : Consejería de Cultura y Medio Ambiente, 1994

GÓMEZ RUIZ, Ricardo. Molinos en el río Odiel : un estudio de arqueología industrial en los límites de EI Andévalo. [Sevilla] : Consejería de Medio Ambiente, D.L. $2003 *$

GONZÁLEZ PARRILLA, José Ma. Catálogo-Guía del Museo Etnográfico de El Cerro de Andévalo (Huelva). [El Cerro de Andévalo (Huelva) : Ayuntamiento de El Cerro de Andévalo, 2003] *

HERNÁNDEZ LEÓN, Elodia... [et al.] Fiesta y frontera : transformaciones de las expresiones simbólicas en la franja fronteriza de Huelva. Sevilla : Junta de Andaluciá, Consejería de Cultura, Empresa Pública de Gestión de Programas Culturales, D.L. 1999, Etnología. (Monografias) *
JIMÉNEZ DE MADARIAGA, Celeste. Danzantes y afines. La danza de los Cascabeleros de Alosno. Revista de Dialectología y tradiciones populares. Tomo 61, cuaderno 1, 2006, p. 157-178

JIMÉNEZ DE MADARIAGA, Celeste. Más allá de Andalucia: reproducción de devociones andaluzas en Madrid. Fundación Blas Infante, 1997

LIMÓN DELGADO, Antonio. Las danzas religiosas masculinas en el Andévalo. Narria : estudios de artes y costubres populares, no 81-82-83-84, juniodiciembre 1998 *

LímÓN DELGADO, Antonio. Etnología del Andévalo (Huelva). Tesis inédita de la Universidad Complutense de Madrid, Facultad de Geografía e Historia, 1976

MADOZ, Pascual. Diccionario geográficoestadistico-histórico de Andalucía : Huelva. Valladolid: Ámbito, 1988. Reprod. facsímil parcial de Diccionario geográfico-estadistico-histórico de España y sus posesiones de ultramar de Pascual Madoz, Madrid : 1845-1850*

MORÓN MONGE, María del Carmen. El Andévalo Occidental : guía turística. Alosno (Huelva) : Asociación para el desarrollo rural del Andévalo Occidental, [2008]

NÚÑEZ ROLDÁN, Francisco. En los Confines del Reino. Huelva y su Tierra en el Siglo XVIII. Sevilla. Secretariado de Publicaciones de la Universidad de Sevilla, 1987

QUINTERO MORÓN, Victoria. Las matanzas. Viejas y nuevas estrategias domésticas. Huelva : Diputación Provincial de Huelva, 2001 *

\section{QUINTERO MORÓN, Victoria; CÁCERES FERIA,}

Rafael. Transformaciones sociales en el Andévalo desde la perspectiva de un ritual tradicional. Demófilo : revista de cultura tradicional de Andalucía, no 20, 1996, p. 79-100 *

RAMÍREZ COPEIRO DEL VILLAR, Jesús. Valverde a través de la fotografía (1840-1940). Valverde del Camino, Huelva: Jesús Ramírez Copeiro del Villar, 1987 *

Nota: Bibliografia resumida de la sección. Para una mayor información puede dirigirse a la Biblioteca del IAPH. Las publicaciones marcadas con asterisco $\left(^{*}\right)$ se encuentran disponibles para su consulta en la Biblioteca del IAPH. 